\title{
Mechanical Analysis of Bamboo and Agro-industrial Residue One-layer Particleboard
}

\author{
Sílvia M. Nasser, ${ }^{\text {a }}$ Elen A. M. Morales, ${ }^{\mathrm{b}},{ }^{*}$ Luiz E. R. Pereira, ${ }^{\mathrm{a}}$ Rafael A. P. Eugenio, ${ }^{\mathrm{a}}$

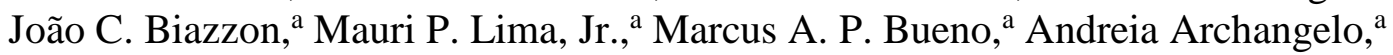 \\ Valter R. B. Celestino, ${ }^{\text {a } H a n i l t o n ~ M . ~ N a s s e r, ~}{ }^{\mathrm{a}}$ Larissa G. Dias, ${ }^{\mathrm{a}}$ Marcelo R. Munhoz, ${ }^{\mathrm{a}}$ \\ Gustavo J. C. Gonçalves, ${ }^{\mathrm{a}}$ Ricardo Breganon, ${ }^{\mathrm{c}}$ and Ivaldo D. Valarelli ${ }^{\mathrm{a}}$
}

\begin{abstract}
A high-density particleboard composed of peanut shells (Arachis hypogaea L.), an agro-industrial residue, and bamboo wastes of the species Dendrocalamus giganteus (branches and apical part), bonded with a two-component polyurethane resin based on castor oil (Ricinus communis L.) in the proportion of $12 \%$ of the particleboard mass, was produced. Four types of specimens were prepared according to the percentage of peanut shells: $0 \%, 10 \%, 20 \%$, and $30 \%$. Mechanical characteristics were evaluated through the flexural strength tests for modulus of rupture, modulus of elasticity, perpendicular traction, and screw pull resistance. The particleboard reached an average density of $917.2 \mathrm{~kg} / \mathrm{m}^{3}$, meaning that it could be classified as high-density particleboard. The results of the mechanical tests indicated that the specimens containing a mixture in the proportion of $90 \%$ bamboo and $10 \%$ peanut hull presented the best mechanical strength. The experiment produced particleboards with a satisfactory mechanical physical performance that met the standards ABNT NBR 14.810-2 and ANSI A2081 , supporting the use of the peanut shell residue in the manufacture of particleboards to be used in internal environments and allowing the applicability of this residue through additional value.
\end{abstract}

Keywords: Sustainability; Agro-industrial waste; Particleboards; Mechanical strength; Bamboo

Contact information: a: Mechanical Engineering Department, UNESP - Unesp - Univ Estadual Paulista, Avenida Luiz Edmundo Carrijo Coube, Bauru, São Paulo 14-01 Brazil; b: Wood Industrial Engineering Department, UNESP - Univ Estadual Paulista, Rua Geraldo Alckmin, Itapeva, São Paulo 519 Brazil; c: Federal Institute of Paraná, Avenida Dr. Tito, Jacarezinho, Paraná 801 Brazil;

*Corresponding author: silvianasser@gmail.com

\section{INTRODUCTION}

The current consumer society encourages the indiscriminate exploitation of the planet's natural resources beyond its renewal limit, and therefore more waste than nature can absorb is released into the environment. Thus, consequences arise such as climate change, extinction of plant and animal species, scarcity of natural resources, and pollution (Iwakiri 2005).

Today, society experiences the benefits of scientific and technological advances with the advent of the industrial revolution that have intensified over the last two centuries. Related to this development is the damage caused to the environment and the various forms of pollution. Therefore, the environmental issue becomes of international scope, leading to the awareness of environmental preservation and the search for mechanisms to prevent further environmental damage. Rethinking the concepts and investing in new alternatives 
for resource management and the correct disposal of waste, to minimize the impacts already underway, is necessary for the future of the next generations (Iwakiri 2005). Agglomerated panels based on lignocellulosic waste can be an alternative for the reuse of agro-industrial waste and the reduction of wood as a raw material for the civil construction and furniture industries.

Brazil is the country with the highest number of bamboo species in Latin America, with 134 species, equivalent to $10 \%$ of the world diversity (Thomazelli 2016). Bamboo is a renewable raw material with low density, high flexibility, and low cost and whose industrial use is still little explored in the Brazilian commercial sector (Thomazelli 2016). Products processed from this material (e.g., agglomerated and laminated panels) can replace, or even prevent, the predatory cutting and extraction of tropical forests among other natural environments subject to timber extraction. Together with the use of bamboo in the panels, the addition of the waste generated by the agro-industry is a methodology that has been providing good results regarding its applicability and increasing importance in the sectors of economy and environmental preservation. In this way, both peanut shells and excess wastes are successfully being used in the manufacture of particleboards. The percentage of peanut peels left after processing is $30 \%$ of the peanut production and typically are destined for bovine feed and fuel for boilers (Barbirato et al. 2014).

An option for adding value to and creating a better destination for this residue is adding the peanut shells of the particulate to the manufacture of panels, with it having lower costs in relation to the agglomerated wood panels (Chipanski 2016). The mechanical properties of these panels allow their application in several areas of the civil construction, architecture, and furniture industries. Caraschi et al. (2009) show that this scenario is favorable because Brazil presents numerous lignocellulosic residues with potential for use in the manufacture of new materials.

Faced with this reality, the production of panels based on peanut shells and bamboo bark presents an innovative, sustainable, and economic character because its production aims at reducing waste disposal, as well as adding value to a material that would otherwise be discarded or wasted in the processes of manufacturing non-durable consumer goods (Valarelli et al. 2013, 2016).

The main objective of this work was to develop and determine the mechanical strength of a single layer of high-density, homogeneous particle panel through the flexural strength tests for modulus of rupture (MOR), modulus of elasticity (MOE), perpendicular traction, and screw pull resistance for top and face. The density of the panel used was 917.2 $\mathrm{kg} / \mathrm{m}^{3}$. Therefore, the percentage of agglomerated and homogeneous particles of the bamboo species Dendrocalamus giganteus and the agricultural residue from the peanut shells were varied. In addition, an adhesive made with a polyurethane resin based on castor oil was used. The results were analyzed using the standards ANSI A208/1 (1999) and ABNT NBR 14.810-2 (2013).

\section{EXPERIMENTAL}

\section{Materials}

The experimental procedures of this work were guided by the methodologies of ABNT NBR 14.810-2 (2013) and ANSI A208/1 (1999). For the experimental development of this work, homogeneous panels of high-density particleboard $\left(917.2 \mathrm{~kg} / \mathrm{m}^{3}\right)$, obtained from Plural Indústria e Comércio de Produtos Químicos Ltda., located in São Carlos, 
Brazil, were constructed using bamboo particles, peanut shells, and bicomponent resin based on castor oil (polyol and isocyanate). The resin added as a binder for the formation of the mattress and subsequent removal of the specimens was castor oil-based polyurethane, manufactured by Plural Indústria e Comércio de Químics Ltda, located in the city of São Carlos, Brazil, where the polyol is identified with Lecopol E 0921 and isocyanate (prepolymer) Lecopol F 0911. The cost of using castor oil-based polyurethane resin varies according to the percentage of polyol and prepolymer used, and the prepolymer represents approximately $80 \%$ of the resin cost. The bamboo species, obtained from Plural Indústria e Comércio de Produtos Químicos Ltda., São Carlos, Brazil, used was Dendrocalamus giganteus, with stems that were 4.5 years old, from harvest rejects (branches and apical part), and the peanut shells of several species, originating from the food processing industries of Bauru, São Paulo, Brazil (Fig. 1).
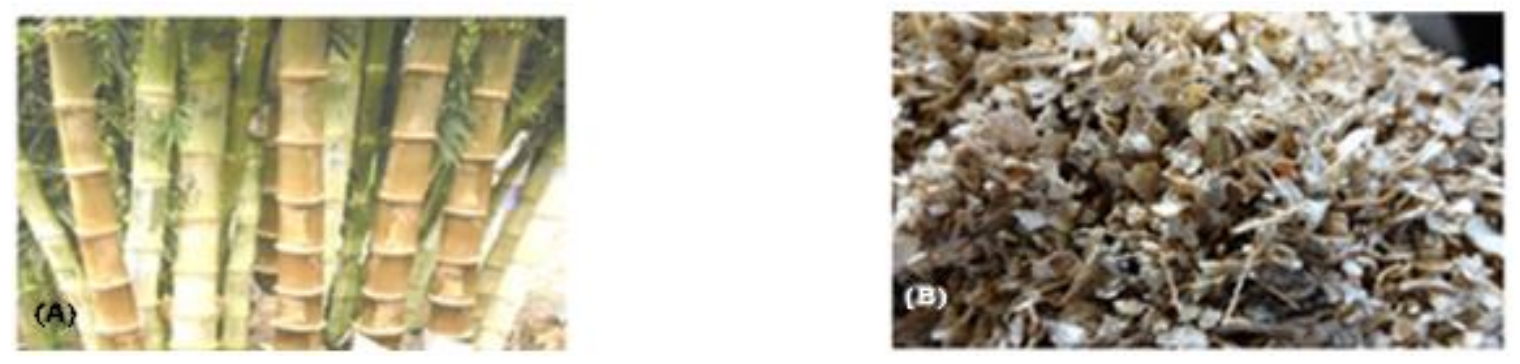

Fig. 1. (a) Bamboo of D. giganteus species and (b) peanut shells waste

The bamboo and peanut shell particles were ground, chopped, and classified in an electric shaker with a set of three sieves $(6.35-\mathrm{mm}, 2.83-\mathrm{mm}$, and $0.84-\mathrm{mm}$ apertures). There was retention and disposal of the "fine particles". The samples were composed of approximately $1300 \mathrm{~g}$ of homogenized particles and pressed with $12 \%$ of the mass being adhesive, resulting in approximately $157.52 \mathrm{~g}$ per unit, with dimensions of $320 \mathrm{~mm} \times 380$ $\mathrm{mm} \times 12.7 \mathrm{~mm}$ (length $\times$ width $\times$ height $)$. Specimens having four compositions were made (Valarelli 2016): 100\% bamboo (B), $90 \%$ bamboo (B) $+10 \%$ peanut shells (A), $80 \%$ bamboo (B) $+20 \%$ peanut shells $(A)$, and $70 \%$ bamboo $(B)+30 \%$ peanut shells $(A)$. The details of the specimens' contents are presented in Table 1.

Table 1. Particleboard Compositions, Adhesive $12 \%$ of Mass

\begin{tabular}{|c|c|c|c|c|c|}
\hline Composition & Material (\%) & $\begin{array}{c}\text { Bamboo } \\
\text { Particles * }(\mathrm{g})\end{array}$ & $\begin{array}{l}\text { Peanut Shell } \\
\text { Particles * }(\mathrm{g})\end{array}$ & $\begin{array}{c}\text { Polyol } \\
\text { Adhesive (g) }\end{array}$ & $\begin{array}{c}\text { Isocyanate } \\
\text { Adhesive } \\
\text { (g) }\end{array}$ \\
\hline T1 & $100 \mathrm{~B}$ & 1312.7 & 0.00 & 78.76 & 78.6 \\
\hline T2 & $90 \mathrm{~B}+10 \mathrm{~A}$ & 1181.4 & 131.30 & 78.76 & 78.76 \\
\hline T3 & $80 B+20 A$ & 1050.10 & 262.60 & 78.76 & 78.76 \\
\hline T4 & $70 B+30 A$ & 918.90 & 393.80 & 78.76 & 78.76 \\
\hline
\end{tabular}

After the homogenization of the components, the adhesive was added by manually mixing, and then mixing for another 5 min with a mechanical stirrer to achieve a homogeneous mixture. Subsequently, the mixture was accommodated in a wood mould $(380 \mathrm{~mm} \times 320 \mathrm{~mm})$ for pre-cold pressing, supported on a stainless-steel sheet coated with 
a polyester film to avoid adhesion of the particles to the sheet. The filling of the mass in the form was done manually to ensure a more homogeneous distribution. This step was fundamental to ensure that there were no changes in the particleboard properties due to the variation of the density between the regions of the mattress (Fig. 2).
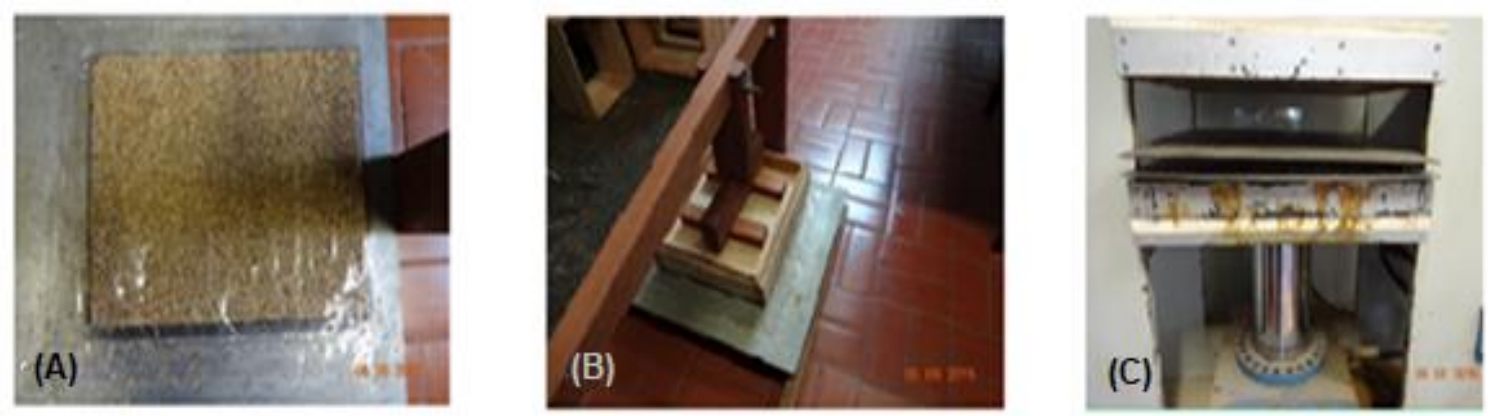

Fig. 2. (a) Mattress with polyester film, (b) manual pressing, and (c) hydraulic pressing

The hydraulic pressing had an objective to provide favorable conditions for compacting the mattresses through the interaction of the variables inherent to the process (i.e., resin curing, pressure, and temperature). The height was limited to $12.7 \mathrm{~mm}$ to establish the final thickness of the panel. The hydraulic press was set to press for $10 \mathrm{~min}$ under an approximate pressure of 195 bar at $110{ }^{\circ} \mathrm{C}$.

After pressing, the particleboards were left in a controlled environment for $72 \mathrm{~h}$ to complete the curing of the resin, and then the specimens were removed according to ABNT NBR 14.810-2 (2013) guidelines. The Hydraulic press used (model PHH 80T) was manufactured by PHS Máquinas Hidráulicas Ltda., Bauru, Brazil.

\section{Methods}

The data obtained were statistically evaluated using Microsoft Excel version 2013 (Microsoft, Redmond, WA, USA) and Minitab version 16.1.1 software (Minitab Inc., State College, PA, USA). These were used to obtain the mean, minimum, maximum, and standard deviation values. The analysis of variance (ANOVA) (Montgomery and Runger 2012) was performed observing the critical $F$ values.

\section{RESULTS AND DISCUSSION}

According to obtained data, there were significant differences between the analyzed values were compared via the Tukey test with a confidence level of $95 \%$. The values obtained for the properties of the panels were compared with the requirements established by the standards ABNT NBR 14.810-2 (2013) and ANSI A208/1 (1999).

\section{MOE and MOR}

For the MOE, composition T2 presented the highest value with a mean of 3053 MPa (Fig. 3). The other composition with the addition of the peanut shells obtained averages between 2801 and $2971 \mathrm{MPa}$, all above the $2300 \mathrm{MPa}$ level recommended by ABNT NBR 14.810-2 (2013) for structural panels in dry conditions and with thickness ranging from $10 \mathrm{~mm}$ to $13 \mathrm{~mm}$ (Valarelli 2016). A negative correlation between the peanut shells content and the MOE value was discovered: a higher percentage of peanut hulls 
resulted in a lower MOE value. However, the composition T1 obtained a mean of 3007 MPa for the MOE test, and it was expected to have a higher value when compared with the other compositions. This may be associated with the chemical composition, microstructure, and defects found in the panel formation, which suggests that further studying is needed.

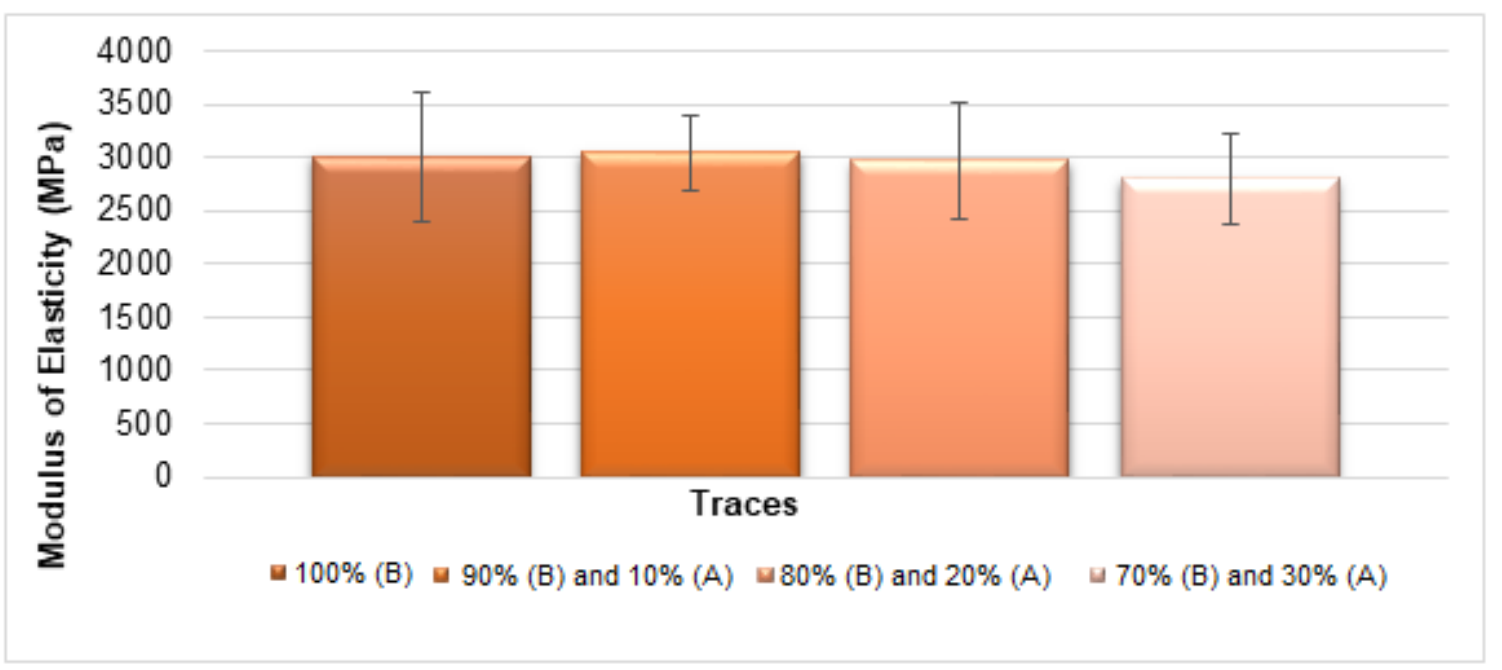

Fig. 3. Results for elasticity tests

The statistical analysis of the effect of the percentage of peanut shells and the amount of bamboo particle on the modulus of elasticity indicated a p-value equal to 0.708 , $\mathrm{F}$ equal to 0.465 , and critical F-value of 2.88 , meaning that there were no significant differences between specimens prepared with the four levels of bamboo, as evidenced by the Tukey test.

The values obtained for MOR were higher than the value $16 \mathrm{MPa}$, determined by ABNT NBR 14.810-2 (2013), for type P4 panels with a thickness of $10 \mathrm{~mm}$ to $13 \mathrm{~mm}$ (Fig. 4). During the tests, composition T1 displayed the highest value with $23.05 \mathrm{MPa}$, and composition 4 had the lowest value of 21.9 MPa. Like the MOE tests, the MOR values increased as more bamboo particles were added to the composites (Valarelli et al. 2013).

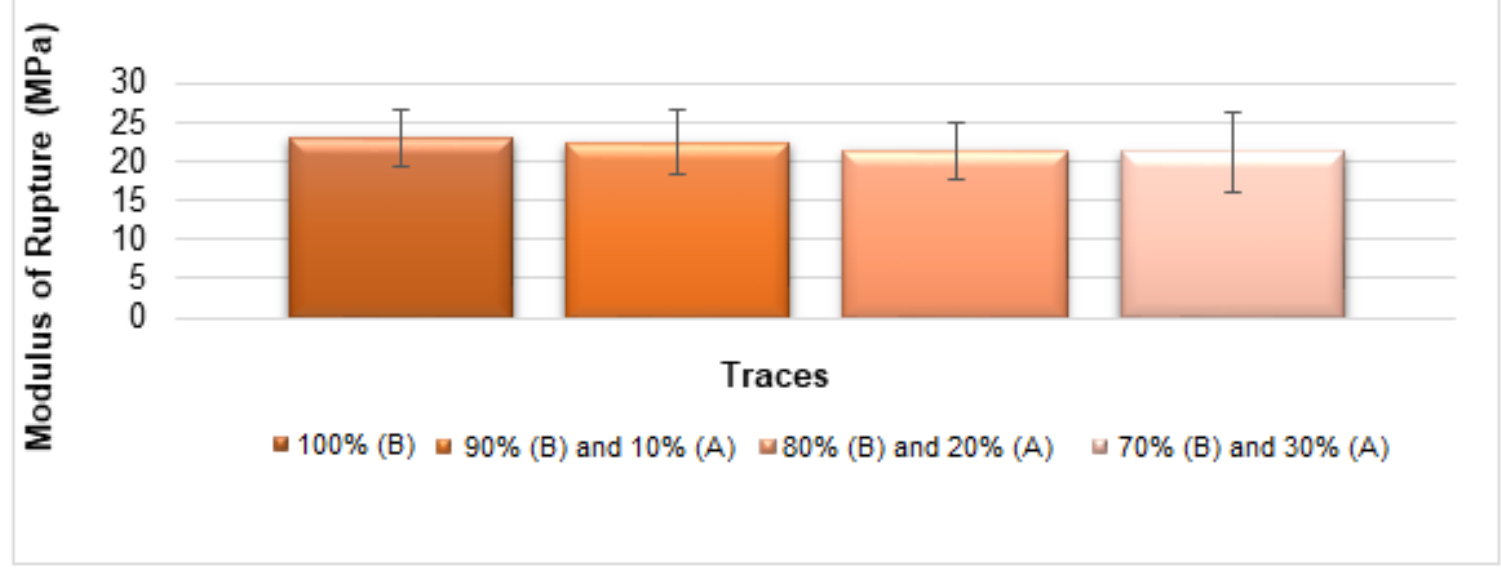

Fig. 4. Modulus of rupture test results 
During the tests, a deformation was observed until a rupture occurred in the test for the T1 composition. In relation to the others, this denoted a greater energy absorption by the panel of bamboo particles. However, the statistical analysis of the effect of the percentage of peanut shells and bamboo in the particleboards on the MOR values indicated a p-value equal to $0.711, \mathrm{~F}$ equal to 0.461 , and critical $\mathrm{F}$ value of 2.86 , which meant there were no significant differences between the specimens prepared with different levels of bamboo.

\section{Perpendicular Traction Resistance Test}

For the perpendicular traction test, the best result was 4.67 MPa for the composition $\mathrm{T} 1$, with the other compositions reaching the average value of $2.21 \mathrm{MPa}$. The standard ABNT NBR 14.810-2 (2013) determined that for the test of resistance to perpendicular traction, the maximum reference value for P4 panels with a thickness of $10 \mathrm{~mm}$ to $13 \mathrm{~mm}$ was $0.40 \mathrm{MPa}$. Therefore, the result for all compositions in this study were above the limit recommended by the standard (Fig. 5).

The statistical analysis on the effect of the percentage of peanut shells and bamboo in the particleboards on the perpendicular traction test indicated a p-value equal to $0.000023, \mathrm{~F}$ equal to 11.25 , and critical F-value of 2.76. Thus, there were significant differences for the two groups between the compositions T1 and T3, belonging to group 1, and composition T4, belonging to group 2, as evidenced by the Tukey test.

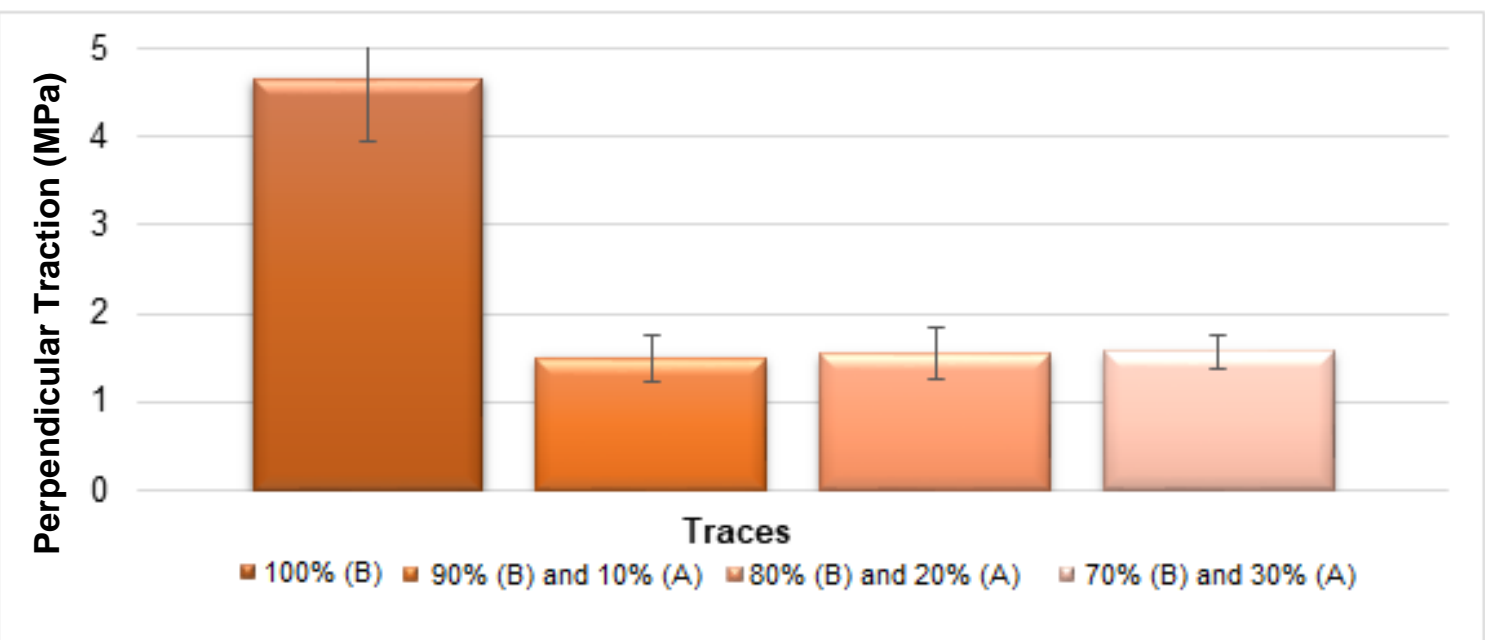

Fig. 5. Perpendicular traction resistance test results

\section{Screw Pull Resistance Determination Test}

The best result for the top screw pull resistance test was for the composition T1 with $2669.24 \mathrm{~N}$. The compositions T2, T3, and T4 registered an average value of $2270 \mathrm{~N}$, ranging between 1942 and 2669 N. For this test, ABNT NBR 14.810-2 (2013) does not establish a reference value for any type of particleboard; however, ANSI A208/1 (1999) recommends a minimum value of $1550 \mathrm{~N}$. Therefore, all the compositions obtained values superior to the one recommended by the norm. Statistical analysis of the effect of the peanut shells content on the bamboo particles on the top screw pull resistance indicated a p-value of 0.708 , F-value of 0.465 , and critical F-value of 2.88 , which denoted the homogeneity of the compositions and was corroborated by the Tukey test that grouped them into group 1 (Fig. 6). 
For the surface screw pull resistance tests (Fig. 7), composition T1 had the best value of $2798 \mathrm{~N}$. The average for the other compositions was $2339 \mathrm{~N}$, with their values ranging between 2036 and 2798 N. For this test, ABNT NBR 14.810-2 (2013) does not establish a reference value; however, ANSI A208/1 (1999) recommends a minimum value of $1550 \mathrm{~N}$. Therefore, all compositions exceeded that determined by the norm. Statistical analysis of the effect of the peanut shells content on the bamboo particles on the face screw pull resistance indicated a p-value of 0.00025 , F-value equal to 8.26 , and critical F-value of 2.86. The Tukey test grouped the compositions T2, T3, and T4 into group 2 and T1 into group 1, as shown in Fig. 7, which indicates the standard deviation among the groups.

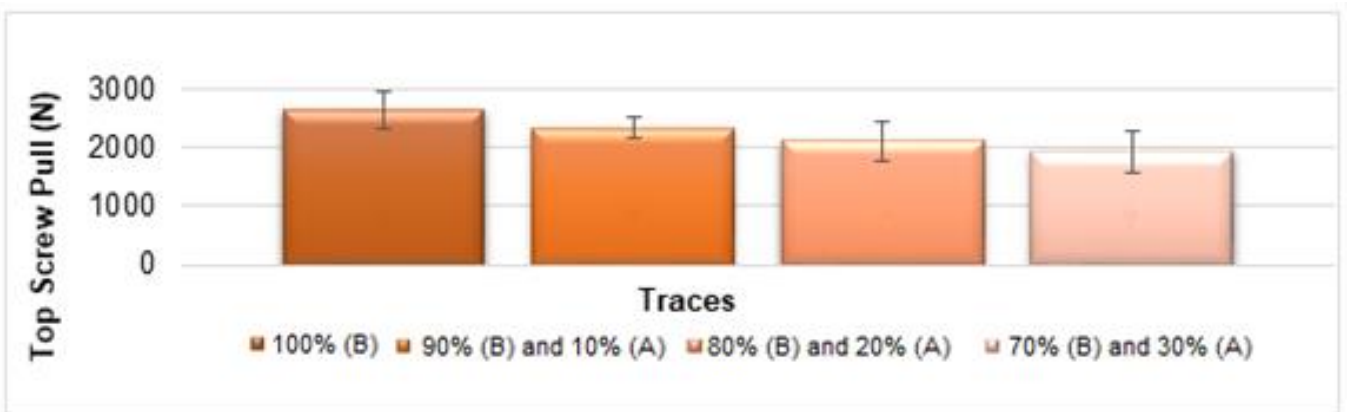

Fig. 6. Top screw pull resistance

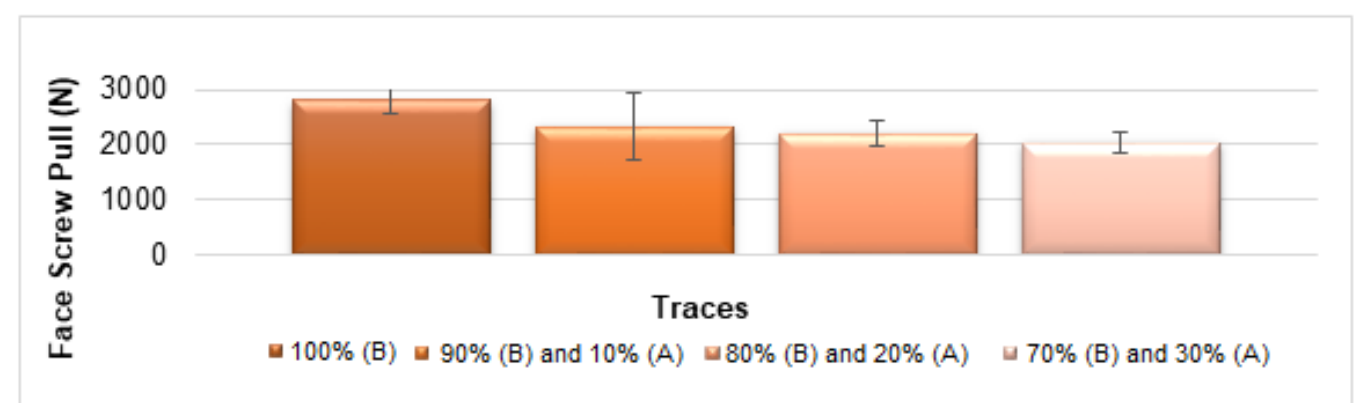

Fig. 7. Face screw pull resistance

\section{CONCLUSIONS}

1. The experiment produced particleboards with a satisfactory mechanical physical performance that met the standards ABNT NBR 14.810-2 (2013) and ANSI A208-1 (1999). The parameters of the material quantity, particle size control, pressure, temperature, and adhesive content were controlled during the manufacturing process to ensure that the standards of the particleboards produced were met.

2. Comparing the composition T1 of Figs. 3 to 7 with the others showed that the addition of peanut shell residue to the mass resulted in a decrease of the values of the mechanical resistance of the particleboards.

3. All the compositions studied met the parameters established by the standards applied in this work, thus supporting the use of the peanut shell residue in the manufacture of particleboards to be used in internal environments and allowing the applicability of this residue through additional value. 


\section{ACKNOWLEDGEMENTS}

The authors would like to thank the institutes UNESP, USP and IFPR that have made available their facilities for measurement, testing and data processing of this research.

\section{REFERENCES CITED}

ABNT NBR 14.810-2 (2013). "Medium density particle panels - Part 1: Terminology, and part 2: Requirements and methods of testing," Brazilian Association of Technical Standards, Rio de Janeiro, Brazil.

ANSI A208-1 (1999). "Particleboard," American National Standards, Washington, D.C. Barbirato, G., Fiorelli, J., Barrero, N. G., Pallone, E. M. J. A., Lahr, F. A. R., Cristoforo, A. L., and Savastano, Jr., H. (2014). "Hybrid particleboard panel of peanut peel reinforced with wood particles," Ciência Florestal 24(3), 685-697.

Caraschi, J. C., Leão, A. L., and Chamma, P. V. C. (2009). "Evaluation of panels produced from solid waste for application in architecture," Polímeros: Ciência e Tecnologia 19(1), 47-53.

Chipanski, E. R. (2016) Proposition for Improving Environmental Performance of the Cluster Industry in Brazil. Editora UFPR, Curitiba/PR, Brazil.

Iwakiri, S. (2005). "Plywood sheets," in: Painéis de Madeira Reconstituída, FUPEF, Curitiba/PR, Brazil, pp. 123-125.

Montgomery, D. C., and Runger, G. C. (2012). Applied Statistics and Probability for Engineers, Editora LTC, Rio de Janeiro, Brazil.

Thomazelli, B. P. (2016). Report: Fabrication and Evaluation of Bamboo Chipboard Panels with Peanut Bark Addition, Editora UNESP, Bauru/SP, Brazil.

Valarelli, I. D. (2016). Alternative Materials Particle Panels: Production and Performance Evaluation, Editora UNESP, Bauru/SP, Brazil.

Valarelli, I. D., Azambuja, M. A., Batistelli, R. A. G., and Campos, C. I. (2013). "Performance evaluation of agglomerated particleboard of bamboo of the species Dendrocalamus giganteus," Encontro Brasileiro em Madeiras e em Estruturas de Madeira 15(5), 115-123.

Article submitted: May 21, 2019; Peer review completed: October. 18, 2019; Revised version received and accepted: February 1, 2020; Published: February 5, 2020.

DOI: $10.15376 /$ biores. 15.2.2163-2170 